\title{
Effects of $\boldsymbol{m}$-Chlorophenylpiperazine on Regional Brain Glucose Utilization: A Positron Emission Tomographic Comparison of Alcoholic and Control Subjects
}

\author{
Daniel Hommer, ${ }^{1}$ Paul Andreasen, ${ }^{1}$ Daniel Rio, ${ }^{1}$ Wendol Williams, ${ }^{1}$ Urs Ruttimann, ${ }^{1}$ Reza Momenan, ${ }^{1}$ \\ Alan Zametkin, ${ }^{2}$ Robert Rawlings, ${ }^{1}$ and Markku Linnoila ${ }^{1}$ \\ ${ }^{1}$ Laboratory of Clinical Studies, Division of Intramural Clinical and Biological Research, National Institute on Alcohol Abuse \\ and Alcoholism, and ${ }^{2}$ Child Psychiatry Branch, National Institute of Mental Health, National Institutes of Health, Bethesda, \\ Maryland 20892-1256
}

$m$-Chlorophenylpiperazine (mCPP) is a mixed serotonin agonist/antagonist used extensively in psychiatric research. Alcoholics show blunted neuroendocrine responses to mCPP, and in some settings mCPP can induce craving for alcohol, particularly among early onset alcoholics. We used $2-\left[{ }^{18} \mathrm{~F}\right]-2-$ deoxyD-glucose positron emission tomography to examine the effects of intravenously administered mCPP $(0.08 \mathrm{mg} / \mathrm{kg})$ on brain glucose utilization in a group of 18 male alcoholics and 12 healthy male control subjects. Differences between two sequential scans (the first followed placebo and the second followed mCPP) were evaluated statistically with a Gaussian random field-based method. Among healthy volunteers mCPP significantly increased brain glucose metabolism in the right medial and posterior orbital gyrus, the cerebellar hemispheres bilaterally, the left nucleus accumbens, the head of the caudate nucleus bilaterally, the anterior and medial-dorsal nuclei of the thalamus bilaterally, the middle frontal gyrus, the left insular cortex, the left middle temporal gyrus, and the posterior cingulate gyrus. Among alcoholic subjects mCPP significantly increased brain glucose metabolism in larger areas of the cerebellum and posterior cingulate than it did in healthy volunteers, but compared with the healthy volunteers, alcoholics showed a smaller area of mCPP-induced activation in the thalamus, almost no activation in the orbital cortices, and no activation at all in the head of the caudate nucleus or the middle frontal gyrus. These results suggest that a serotoninergic challenge activates basal ganglia circuits involving orbital and prefrontal cortices among healthy volunteers but that the response of these circuits is blunted among alcoholics.

Key words: alcoholism; serotonin; PET; m-chlorophenylpiperazine; striatum; thalamus; orbital cortex; frontal cortex
$m$-Chlorophenylpiperazine ( $\mathrm{mCPP})$ is a metabolite of the antidepressant trazodone that possesses agonist properties at some 5-HT receptors and antagonist properties at others. It has highest affinity for the $5 \mathrm{HT}_{2 \mathrm{C}}$ receptor, where it acts as a partial agonist (Sanders-Bush and Breeding, 1990). It also binds to the $5 \mathrm{HT}_{3}$ and $5 \mathrm{HT}_{2 \mathrm{~A}}$ receptors, where it acts as an antagonist. In addition, mCPP binds to the $5 \mathrm{HT}_{1 \mathrm{~A}}, 5 \mathrm{HT}_{7}$, and $5 \mathrm{HT}_{6}$ receptors but with an affinity more than an order of magnitude lower than its affinity for the $5 \mathrm{HT}_{2 \mathrm{C}}$ receptor (Hoyer, 1988; Hamik and Peroutka, 1989; Schoeffter and Hoyer, 1989). Despite its nonspecific pharmacology $\mathrm{mCPP}$ has been used extensively in psychiatric research to gauge the sensitivity of the serotonin (5-HT) system of the brain.

Recently, our group (Benkelfat et al., 1991) as well as Krystal et al. (1994) reported that when mCPP is administered to alcoholics it induces a "craving" for alcohol. This effect appears most dramatically among early onset or type II alcoholics. In addition, both we (George et al., 1997) and Krystal et al. (1996) found blunted cortisol and adrenocorticotrophic hormone (ACTH) responses to mCPP among alcoholics. The blunted ACTH and cortisol re-

Received Oct. 2, 1996; revised Jan. 17, 1997; accepted Jan. 27, 1997.

We thank Dr. Dennis Murphy for providing the $m$-chlorophenylpiperazine used in this study and for his valuable comments on an earlier version of this manuscript. We also thank Mr. Michael Kerich for his tireless and patient technical assistance.

Correspondence should be addressed to Dr. Daniel Hommer, National Institute on Alcohol Abuse and Alcoholism, National Institutes of Health, Building 10, Room 3C102, 10 Center Drive, Bethesda, MD 20892-1256.

Copyright (C) 1997 Society for Neuroscience $0270-6474 / 97 / 172796-11 \$ 05.00 / 0$ sponses seem consistent with a reduced sensitivity to $5 \mathrm{HT}_{2 \mathrm{C}}$ agonists among alcoholics. However, if alcoholics are less sensitive to $5 \mathrm{HT}_{2 \mathrm{C}}$ agonists, then why does $\mathrm{mCPP}$ produce a more intense and qualitatively different subjective response (craving) among some alcoholics?

The combination of blunted neuroendocrine responses and more intense and qualitatively different subjective responses is not unique to alcoholics. There are several reports of blunted neuroendocrine responses to $\mathrm{mCPP}$ among individuals with other psychiatric disorders. In contrast to blunted neuroendocrine responses, subjective responses to $\mathrm{mCPP}$ often are more pronounced among individuals with psychiatric disorders (for review, see Kahn and Wetzler, 1991). There is some controversy as to whether the more dramatic subjective responses among psychiatric patients result from greater anxiety that follows $\mathrm{mCPP}$ or from a specific exacerbation of the primary psychiatric symptoms of the particular disorder (presumably mediated via a specific serotoninergic mechanism). Nevertheless, subjective responses to $\mathrm{mCPP}$ often seem to be similar to the primary psychiatric symptoms of the subjects being studied.

The purpose of this study was twofold. First, we hoped to characterize the effect of mCPP administration on the regional cerebral metabolism of glucose (CMRglc) among healthy male volunteers. Second, we hoped to compare the CMRglc that follows mCPP among alcoholics and healthy volunteers to determine which, if any, brain regions responded differently. In addition, we measured the changes in prolactin and ACTH after mCPP so that this study could 


\begin{tabular}{|c|c|c|c|c|c|c|c|}
\hline $\begin{array}{l}\text { Subject } \\
\text { ID }\end{array}$ & Age & $\begin{array}{l}\text { Alcoholic } \\
\text { type }\end{array}$ & $\begin{array}{l}\text { Past axis I DSMIIIR } \\
\text { diagnoses }^{a} \\
\text { (in addition to alcohol } \\
\text { dependence) }\end{array}$ & $\begin{array}{l}\text { Axis II DSMIIIR } \\
\text { diagnoses }^{b}\end{array}$ & $\begin{array}{l}\text { Years of } \\
\text { heavy } \\
\text { drinking }\end{array}$ & $\begin{array}{l}\text { Cummulative } \\
\text { alcohol } \\
\text { consumption } \\
(\mathrm{kg})\end{array}$ & $\begin{array}{l}\text { MAST } \\
\text { score }\end{array}$ \\
\hline 1 & 51 & I & None & None & 4 & 258 & 22 \\
\hline 2 & 55 & I & Simple phobia & BOR, self-defeating & 21 & 532 & 30 \\
\hline 3 & 29 & I & Dep. NOS & None & 13 & 230 & 22 \\
\hline 4 & 52 & I & None & None & 5 & 101 & 29 \\
\hline 5 & 35 & I & $\begin{array}{l}\text { MDD, dysthymia, } \\
\text { polysubstance abuse }\end{array}$ & BOR & 16 & 246 & 61 \\
\hline 6 & 32 & I & MDD, GAD, alc. hall., & BOR, AS, AVOID & 15 & 236 & 46 \\
\hline 7 & 44 & I & None & None & 26 & 558 & 36 \\
\hline 8 & 45 & I & $\mathrm{MDD}, \mathrm{GAD}$ & None & 27 & 1649 & 36 \\
\hline 9 & 25 & II & Dep. NOS & None & 5 & 52 & 42 \\
\hline 10 & 22 & II & MDD, PTSD, dysthymia & BOR, AVOID & 4 & 145 & 38 \\
\hline 11 & 44 & II & Dep. NOS & None & 26 & 140 & 18 \\
\hline 12 & 30 & II & MDD, alc. hall. & AS & 10 & 186 & 63 \\
\hline 13 & 33 & II & None & None & 16 & 544 & 45 \\
\hline 14 & 43 & II & None & None & 37 & 500 & 42 \\
\hline 15 & 29 & II & $\begin{array}{l}\text { MDD, polysubstance } \\
\text { abuse, alc. hall. }\end{array}$ & None & 17 & 1374 & 63 \\
\hline 16 & 30 & II & alc. hall. & AS & 22 & 636 & 53 \\
\hline 17 & 33 & II & None & None & 17 & 1264 & 51 \\
\hline 18 & 36 & II & Polysubstance abuse & None & 26 & 2704 & 239 \\
\hline
\end{tabular}

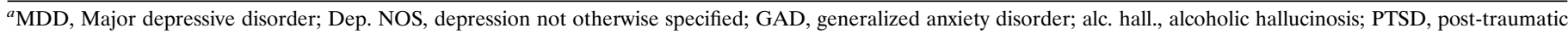
stress disorder.

${ }^{b}$ BOR, Borderline personality disorder; AS, antisocial personality disorder; AVOID, avoidant personality disorder.

be compared with the many studies that have measured endocrine responses to mCPP. Finally, we examined subjective ratings of emotional responses to $\mathrm{mCPP}$ in both groups to determine whether "craving" for alcohol could be induced pharmacologically in a nuclear medicine setting and whether subjective reports of feeling states and neuroendocrine responses were associated with a specific pattern of regional CMRglc responses.

\section{MATERIALS AND METHODS}

To measure the effects of mCPP on global and regional cerebral metabolism of glucose (CMRglc), healthy male volunteers $\left(N_{1}=12\right)$ and abstinent male alcoholics $\left(N_{2}=18\right)$ received two sequential $2-\left[{ }^{18} \mathrm{~F}\right]-2$ deoxy-D-glucose positron emission tomographic $\left({ }^{18} \mathrm{FDG}\right.$ PET) scans during a single-blinded, placebo-controlled, intravenous (IV) mCPP (0.08 $\mathrm{mg} / \mathrm{kg}$ ) challenge.

Subjects. All subjects provided informed consent and were screened with the Structured Clinical Interview for the Diagnostic and Statistical Manual Volume III-R (DSM III-R; American Psychological Association, 1990) for Axis I and Axis II psychopathology. Alcoholic subjects met DSM III-R criteria for alcohol dependence and had been hospitalized for at least 3 weeks on the alcohol treatment unit of the National Institutes of Health Clinical Center. They had no current Axis I psychiatric disorder other than alcohol dependence. Healthy volunteers and their first degree relatives had no past or present Axis I psychopathology. Alcoholic subjects and healthy volunteers were found to have no abnormalities on medical history; physical examination; ECG; electrolyte; hepatic, mineral, and thyroid laboratory panels; and CBC. In addition, alcoholic subjects were administered the Michigan Alcoholism Screening Test (MAST; Selzer, 1971). Information on recent and past alcohol consumption, as well as alcohol-related behavior, was obtained from structured research questionnaires (Eckardt et al., 1978). All subjects had negative urine drug screens on admission and negative breath alcohol tests throughout their hospitalization (alcoholic subjects) or at each outpatient visit (healthy volunteers). Alcoholics were divided into type I (late onset) and type II (early onset) alcoholics, using the criteria developed by von Knorring et al. (1985). Table 1 shows a summary of the clinical characteristics of the alcoholic subjects.
Subjects ate a low-monoamine diet for $3 \mathrm{~d}$ before the scan and had a light meal $3 \mathrm{hr}$ before the scan. The goal of this dietary regimen was to control the dietary intake of tryptophan and tyrosine, as well as to keep the subjects' blood sugar constant and within normal range throughout the scan.

Scanning procedure. Each subject underwent two sequential ${ }^{18} \mathrm{FDG}$ PET scans on the Scanditronix 1024-7B scanner at the National Institutes of Health Department of Nuclear Medicine. This scanner acquires a volume of PET data consisting of 21 axial images. These 21 images are acquired as three sets of seven interleaved slices. Each set of slices is acquired over $10 \mathrm{~min}$; thus the entire scan requires $30 \mathrm{~min}$. The scanner has a $7 \mathrm{~mm}$ full width at half-maximum (FWHM) in-plane and an $11 \mathrm{~mm}$ FWHM axial resolution. Slice separation is $\sim 3.6 \mathrm{~mm}$. A filtered backprojection method was used to produce image matrices of $128 \times 128$ pixels each, with a size of $2 \times 2 \mathrm{~mm}$. The total time that the subject was lying on the scanner table was $2 \mathrm{hr}$ and $20 \mathrm{~min}$.

The PET scanning sessions proceeded as follows: a radial arterial line was placed in all subjects under local anesthesia with $0.1 \%$ lidocaine. An IV line was placed in the antecubital vein of the opposite arm. The subject then reclined on the scanner table in the supine position. To limit head motion, we fit a thermoplastic mask to the subject's head and attached it to the scanner table. The axial plane of the PET scan camera was aligned to the subject's head at the cantho-meatal line, and an attenuation correction (transmission) scan was performed. The subjects' eyes were covered, and they were asked to remain quiet, awake, and at rest and to attend to their feelings and sensations during the scan. Serial blood samples for ACTH, prolactin, and time-radioactivity quantifications were drawn from the radial artery. ${ }^{18} \mathrm{FDG}$, placebo, and mCPP were administered through the IV line.

The sequential FDG/PET methodology has been described previously (Brooks et al., 1985, 1987; Chang et al., 1987, 1989; Duara et al., 1992). First, an attenuation correction scan was performed (transmission scan). Then the subject received $20 \mathrm{cc}$ of normal saline (placebo for mCPP) over $90 \mathrm{sec}$, which was followed immediately by $3 \mathrm{mCi}$ of ${ }^{18} \mathrm{FDG}$ in $9 \mathrm{cc}$ of solution infused over $60 \mathrm{sec}$. Placebo was always administered first. Serial arterial blood samples were taken to construct a time-activity curve and to measure blood glucose. Beginning $30 \mathrm{~min}$ after the ${ }^{18} \mathrm{FDG}$ infusion, three interleaved sets of $10 \mathrm{~min}$ emission scans were acquired. This 
represented the end of the data collection for the placebo state. Another attenuation correction scan was performed (transmission plus residual emission), and the subject was informed that the second scan was about to start. mCPP, $0.08 \mathrm{mg} / \mathrm{kg}$, in $20 \mathrm{cc}$ of normal saline was infused over 90 $\mathrm{sec}$ intravenously, followed by $5 \mathrm{mCi}$ of ${ }^{18} \mathrm{FDG}$ in $9 \mathrm{cc}$ of normal saline over $60 \mathrm{sec}$. Thirty minutes after the second ${ }^{18} \mathrm{FDG}$ infusion, a second set of three 10 min emission scans was acquired. Then the subjects' infusion lines were removed, and the subjects voided to limit radiation exposure to the urinary bladder.

In addition to the PET brain images, all but one of the alcoholics and all but three of the healthy volunteers had magnetic resonance image (MRI) brain scans. All scans were read as normal by National Institutes of Health Clinical Center radiologists. Eleven subjects had full volumetric coronal (128 slice) scans acquired on a GE-Signa 1.5 Tesla scanner. The remaining subjects were scanned on a 0.5 Tesla scanner.

Blood samples for measurement of ACTH and prolactin were drawn immediately before placebo administration and 30 and $60 \mathrm{~min}$ after placebo administration. Blood also was sampled at six consecutive $10 \mathrm{~min}$ intervals after the mCPP infusion. Blood samples for endocrine measures were placed on ice immediately and centrifuged within $3 \mathrm{hr}$ of collection; plasma was separated and stored at $-70^{\circ} \mathrm{C}$. The concentrations of ACTH and prolactin were determined by Hazleton Laboratories (Vienna, VA) via radioimmunoassay. The effects of mCPP on ACTH and prolactin were evaluated by first performing a repeated ANOVA on the neuroendocrine data from the baseline and two samples after placebo but before mCPP administration. This tested for the effects of placebo on ACTH and prolactin release. Then a repeated ANOVA covarying for ACTH and prolactin concentrations (ANCOVA) immediately preceding $\mathrm{mCPP}$ administration $(60 \mathrm{~min}$ after placebo; see Figs. 1, 2) was performed to examine the effects of $\mathrm{mCPP}$ administration on $\mathrm{ACTH}$ and prolactin release.

Self-ratings were obtained from the subjects while they were inside the scanner immediately before the placebo infusion, $60 \mathrm{~min}$ after the placebo infusion, and $60 \mathrm{~min}$ after the $\mathrm{mCPP}$ infusion. The rating instruments were read to the subjects, and they were instructed to respond verbally on the basis of their experience over the preceding $60 \mathrm{~min}$. The self-ratings consisted of a $0-6$ rating in response to the following questions: (1) How much did you crave a drink? (2) How drunk or intoxicated did you feel? (3) How likely would you be to take a drink of alcohol? (4) How much did you feel like you were going through alcohol withdrawal? (5) How panicky or frightened did you feel?

Image analysis. There are two parts to the analysis of the paired PET scan data obtained in this study. First, all of the image data were mapped onto a standard three-dimensional (3-D) brain template. Spatial registration was done by a fully automated 3-D, whole-brain-matching algorithm that used global spatial transformations of the original brain slices to map them into a standard size and shape (Thevenaz et al., 1995; Unser et al., 1995). Then the 3-D-matched whole-brain image slices were used in a spatial analysis of regional change in brain glucose utilization after $\mathrm{mCPP}$. The theory of Gaussian random field as recently extended by Worsley et al. (1992) was used for this analysis. Both the original observed and relative regional CMRglc were examined. Relative CMRglc was determined by subtracting the mean CMRglc for the entire brain from the observed CMRglc of each pixel. In addition, differences in mean CMRglc of the entire brain between alcoholics and healthy volunteers or between placebo and mCPP infusions in each subject group were examined with independent or paired $t$ tests, respectively.

Spatial registration. Images from one of the healthy volunteers, who had undergone a volumetric 1.5 Tesla MRI scan and whose brain image was qualitatively assessed to be regularly shaped, were chosen as the standard brain template. Earlier work by our group demonstrated that there is significant movement of subjects' heads between periods of PET data acquisition (Ruttimann et al., 1995). The movement occurs even between acquisition of the three sets of seven slices, which constitute a single full head scan. For this reason the three sets of interleaved brain slice images of each subject were rotated rigidly and translated into a common coordinate system established by the first set. Then, using the most general global 3-D affine transformations (see below), we registered the images to the standard brain image. Because the experimental procedure consisted of two sequential image acquisitions, each subject's postdrug images were registered to the predrug images.

Registration was accomplished by determining the required 3-D transformation parameters ( 12 in the general case) such that the average squared difference between the pixel intensities of the two volumes to be registered was minimized. This technique is fully automatic, effectively exploits all the available information content of the data, and has maximum likelihood under the Gaussian white noise assumption. The search space for the transformation parameters was the continuous set of nonsingular 3-D affine transformations, including translation, rotation, and anisotropic scaling. However, for within-subject (e.g., postdrug to predrug image) registration the parameters were restricted to translation and rotation only. Because continuous search-space subpixel sampling was required, the procedure resampled the slice data with the use of a cubic spline model that interpolates the volume. The registration method was iterative in the sense that an initial set of parameter estimates was refined until convergence was reached. To accelerate convergence, we used a coarse-to-fine image resolution strategy that propagated the parameter estimates obtained at a coarse resolution as initial conditions for the next finer resolution level. Within each resolution level a modification of the Marquardt-Levenberg algorithm for nonlinear least-square optimizations was used to obtain the respective parameter estimates (Marquardt, 1963). Then the registered images were resliced by cubic spline interpolation into a set of standard axial image planes. Because of the rotation and translation required for registration and the variation of subject head sizes and head positioning in the scanner, some of the upper or lower axial slices in some subjects were incomplete or outside the slice range of the reference set. Therefore, a subset of 14 contiguous axial slices, which contained complete data from each subject, were chosen for statistical analyses.

Gaussian random field analysis. Two primary statistical analyses of the data were performed to identify localized regions of change. The first analysis examined changes in the observed (often referred to as the "absolute" value) value of brain glucose utilization induced by mCPP. This analysis was performed separately for alcoholic and healthy volunteers. The second statistical analysis compared the changes in observed brain glucose utilization produced by mCPP between groups of healthy volunteer and alcoholic subjects. Because PET data often are "normalized" before they are analyzed statistically, we also analyzed an adjusted relative CMRglc for each pixel. The relative pixel glucose utilization value was determined by subtracting the mean CMRglc for the entire brain from the value of each pixel. This was done separately for the preand post-mCPP scans.

To examine the effect of mCPP on brain glucose utilization, we constructed differences at each of the 14 slice levels for each subject between the 3 -D registered images after drug administration, $p_{\mathrm{jiD}}(\boldsymbol{x})$, and after placebo administration, $p_{\mathrm{jiBL}}(\boldsymbol{x})$,

$$
d_{\mathrm{ji}}(\boldsymbol{x})=p_{\mathrm{jiD}}(\boldsymbol{x})-p_{\mathrm{jiBL}}(\boldsymbol{x}),
$$

where $(x)=(x, y)$ is the two-dimensional coordinate (or pixel) position at each slice level, $j$ represents the groups (alcoholics $=2$, healthy volunteers $=1$ ), and $i$ is used as the subject index. Assuming a stationary Gaussian model for the noise in each subject (Worsley et al., 1992), the difference image can be represented by:

$$
d_{\mathrm{ji}}(\boldsymbol{x})=\mu_{\mathrm{j}}(\boldsymbol{x})+\sigma_{\mathrm{j}} \epsilon_{\mathrm{i}}(\boldsymbol{x}),
$$

where $\mu_{\mathrm{j}}(x)$ is the group-averaged image and the noise for each subject is represented by the spatially averaged (over the subregion of brain chosen for analysis) $\mathrm{SD}, \sigma_{\mathrm{j}}$, times a Gaussian random variable, $\epsilon_{\mathrm{i}}(\boldsymbol{x})$, with zero expectation and unit variance. To increase the power of this model, insure Gaussian-distributed noise, and compensate for localized spatial misregistration, we applied additional smoothing to these images. This consisted of a two-dimensional Gaussian filter, with FWHM of $7 \mathrm{~mm}$ in both the $x$ and $y$ coordinates, applied to each slice for each subject. An estimate of the difference image for each group was calculated as follows:

$$
\hat{d}_{\mathrm{j}}(\boldsymbol{x})=\frac{1}{N_{\mathrm{j}}} \sum_{i=1}^{N_{\mathrm{j}}} d_{\mathrm{ji}}(\boldsymbol{x}),
$$

where $N_{\mathrm{j}}$ is the number of subjects in each group. Next we defined a $z$-map statistical image as:

$$
z_{\mathrm{j}}(\boldsymbol{x})=\frac{\sqrt{N_{\mathrm{j}}} \hat{d}_{\mathrm{j}}(\boldsymbol{x})}{\sigma_{\mathrm{j}}},
$$

which is approximately a Gaussian random field with zero expectation and unit variance. This image was used to test whether there were any regions of localized mCPP-induced activation for either the group of alcoholics or the group of healthy volunteers.

The statistical comparison of the two-group difference, that is whether 
Table 2. Comparison of types I and II alcoholics with healthy volunteers

\begin{tabular}{|c|c|c|c|c|c|c|}
\hline & Age & $\begin{array}{l}\text { Height } \\
(\mathrm{cm})\end{array}$ & Weight $(\mathrm{kg})$ & $\begin{array}{l}\text { Lifetime } \\
\text { alcohol }(\mathrm{kg})\end{array}$ & $\begin{array}{l}\text { Years of heavy } \\
\text { drinking }\end{array}$ & MAST score \\
\hline \multicolumn{7}{|l|}{ Healthy volunteers } \\
\hline$n=12$ & $31.7 \pm 8.9$ & $179.0 \pm 6.0$ & $79.1 \pm 9.9$ & - & - & - \\
\hline Alcoholics $n=18$ & $37.1 \pm 9.7$ & $179.5 \pm 4.8$ & $76.7 \pm 9.9$ & $636 \pm 716$ & $17.7 \pm 9.3$ & $55.3 \pm 50.8$ \\
\hline Type I $n=8$ & $42.9 \pm 9.8^{*}$ & $179.0 \pm 3.3$ & $76.1 \pm 10.5$ & $468 \pm 538$ & $17.1 \pm 8.5$ & $38.3 \pm 13.7$ \\
\hline Type II $n=10$ & $32.5 \pm 7.0^{*}$ & $180.0 \pm 5.9$ & $77.2 \pm 9.9$ & $755 \pm 825$ & $18.0 \pm 10.1$ & $65.4 \pm 62.4$ \\
\hline
\end{tabular}

All values shown as mean $\pm \mathrm{SD}$.

*Significantly different at $p<0.05$.

the drug response in alcoholics was different from that in the healthy volunteers, was performed by calculating a $z$-map statistical image constructed from the difference of mean difference images as follows:

$$
z(\boldsymbol{x})=\sqrt{\frac{N_{2} N_{1}}{N_{2}+N_{1}}} \frac{\hat{d}_{2}(\boldsymbol{x})-\hat{d}_{1}(\boldsymbol{x})}{\sigma},
$$

where:

$$
\sigma^{2}=\frac{\left(N_{1}-1\right) \sigma_{1}^{2}+\left(N_{2}-1\right) \sigma_{2}^{2}}{N_{1}+N_{2}-2} .
$$

Three $z$-map images (within-group change after administration of mCPP in alcoholics and healthy volunteers and between-group differences of mCPP-induced change for alcoholics and healthy volunteers) were evaluated for localized statistical significance. This was accomplished by applying the theory of Gaussian random fields to adjust for multiple testing (associated with testing each image pixel) and to establish a threshold for activation on the basis of the number of resolution pixels or resels:

$$
\text { resels }=\operatorname{area} /\left(\mathrm{FWHM}_{\mathrm{x}} \times \mathrm{FWHM}_{\mathrm{y}}\right),
$$

where FWHM in each dimension was taken as the square root of the sum of squares of the observed FWHM of the PET scanner and the applied Gaussian smoothing function. In the case of the within-group test, the area was restricted at each slice level to include only the region within the standard brain. The activation threshold, $t$ (Adler, 1981; Worsley et al., 1992), was selected such that the probability of the random field $z$ exceeding $t$, as given by:

$$
p(z>t) \approx \operatorname{resels}(4 \ln 2)(2 \pi)^{-3 / 2} t e^{-t^{2} / 2},
$$

was smaller than $\alpha=0.08$ divided by 14 , which provided a Bonferroni correction for testing each of the 14 slices chosen for analyses. This gave an $\alpha$ level per slice of 0.0057 . Before the testing of the $z$-map image, a test was performed to see whether the variance was homogenous within each slice, with an $\alpha=0.0014$ per slice ( 0.02 divided by 14$)$. Note that with this selection of the $\alpha$ levels for the two tests the experiment-wise $\alpha$ level is $0.08+0.02=0.10$.

Finally, on the basis of examination of the entire brain response to mCPP in both alcoholics and healthy volunteers, two areas were tested for differences in drug responses between groups. One of these areas was a subset of the brain containing the basal ganglia and thalamus. The other area contained the orbital frontal region only.

Spatial registration of PET to MRI image. Using a modified version of an algorithm (Besel and McKay, 1992) developed to calculate the 3-D transformation parameters necessary to match the two surfaces spatially, we registered the standard PET brain image to an MRI brain image acquired for the same subject. This algorithm used the midsagittal fissure, the inferior surfaces of the frontal and occipital lobes, the outer table of the skull from a volumetric MRI scan, and the same landmarks identified in the PET emission and transmission (for the outer table of the skull) brain images. Although this method allows for regular 3-D affine transformation, only translation and rotation transformations were allowed, because the scaling parameters could be determined with sufficient accuracy from the scanner pixel dimensions. This method is based on an iterative closest point algorithm and, once the surfaces have been chosen, uses a set of points and the corresponding points with the closest distance located on the matching surface for each iteration. Homologous points on the two surfaces are found automatically by the algorithm. Then the transformation parameters are estimated from the displacement vectors of these nearest points.

\section{RESULTS}

\section{Subject characteristics}

Table 2 shows the characteristics of the alcoholic and control subjects and compares the alcoholics by subtype. The alcoholics and healthy volunteers did not differ significantly in age, height, or weight. The type I alcoholics were significantly older than the type II alcoholics ( $t$ test for independent samples, $t_{(16)}=-2.61, p<$ $0.02)$. In addition, the type II alcoholics had greater estimates of lifetime alcohol consumption and higher MAST scores. However, the differences in lifetime alcohol consumption and MAST scores did not reach significance because of the high variance of these measures in our sample of type II alcoholics. Despite their difference in age, type I and type II alcoholics did not differ in the number of years of heavy drinking.

\section{Subjective ratings}

After the mCPP infusion there were no significant differences between alcoholics and controls on any of the subjective ratings of sensations related to alcohol use. None of the subjects, neither alcoholics nor controls, reported any experience of "craving" for alcohol during the study. All ratings on the "craving" question, at all times, were 0 . Six subjects (3 alcoholics and 3 controls) reported some degree of feeling "drunk" after mCPP. Three subjects ( 2 alcoholics and 1 control) reported that they were likely to take a drink (if one were offered) after mCPP.

Because all subjects rated panicky feelings as 0 at baseline, we evaluated the effects of mCPP on panicky feelings with the Wilcoxon matched pairs test. mCPP produced a significant increase in ratings of feeling panicky among the healthy volunteers $(Z=2.36$, $p<0.02)$. Among the entire group of alcoholic subjects there was a trend for mCPP to increase ratings of panic $(Z=1.78, p<0.10)$. When type I and type II alcoholics were examined separately, type II alcoholics showed a significant increase in panicky feelings $(Z=$ 2.02, $p<0.05$ ), whereas type I alcoholics showed no significant effect.

\section{Neuroendocrine effects of mCPP}

Repeated measures ANOVA revealed that placebo administration had no significant effect on ACTH or prolactin concentrations among either the alcoholics or healthy volunteers.

The ability of mCPP to increase ACTH was blunted significantly in alcoholics as compared with healthy volunteers (repeated measure ANCOVA group effect, $F_{(1,27)}=4.54, p<0.05$ ) (Fig. $1)$. The interaction between group (healthy volunteers vs alcoholics) and time after mCPP infusion was also significant $\left(F_{(5,140)}=\right.$ $3.40, p<0.01)$, indicating different time courses for responses. In contrast, there were no significant differences in $\mathrm{mCPP}$ effects on 


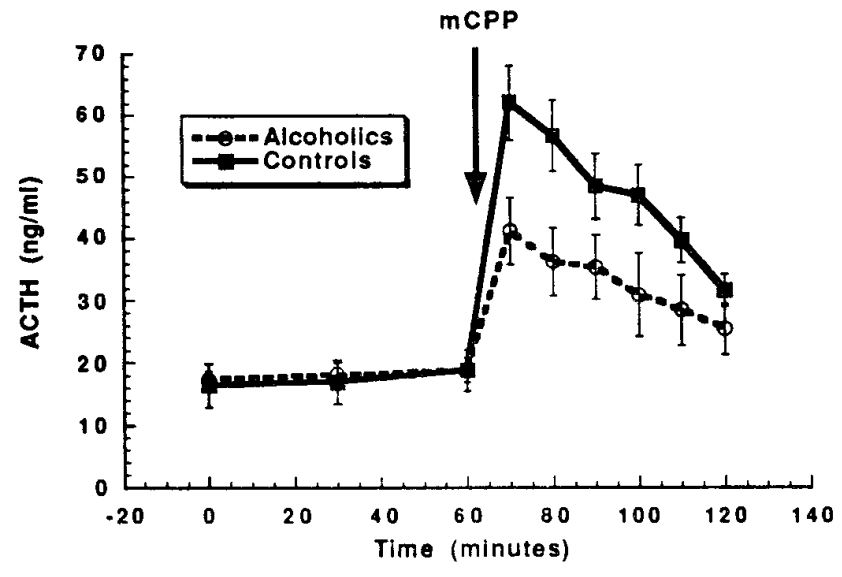

Figure 1. Alcoholics show a significantly smaller increase in adrenocorticotrophic hormone after mCPP infusion as compared with healthy volunteers. The error bars represent SE. See Results, Neuroendocrine effects of $\mathrm{mCPP}$, for statistical analysis.

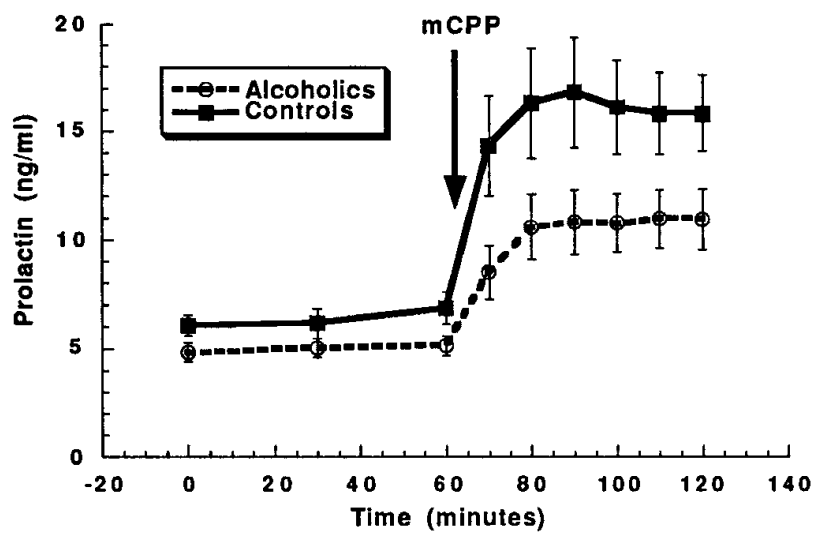

Figure 2. Although alcoholics seem to have a blunted prolactin response to $\mathrm{mCPP}$ infusion as compared with healthy volunteers, when adjusted for initial differences in prolactin, response to $\mathrm{mCPP}$ did not differ significantly between the groups. The error bars represent SE. See Results, Neuroendocrine effects of mCPP, for statistical analysis.

ACTH between type I and type II alcoholics (repeated measures ANCOVA group effect, $F_{(1,27)}=1.1, p=0.32$; group $\times$ time interaction, $\left.F_{(5,80)}=0.38, p=0.86\right)$.

Although healthy volunteers had a larger prolactin response to $\mathrm{mCPP}$, the differences in responses between alcoholics and healthy volunteers did not reach statistical significance (repeated measures ANCOVA group effect, $F_{(1,26)}=1.95, p=0.17$ group $\times$ time interaction, $\left.F_{(5,140)}=0.31, p=0.90\right)$ (Fig. 2). Similarly, there were no significant differences in prolactin responses between type I and type II alcoholics (repeated measure ANCOVA group effect, $F_{(1,26)}=1.95, p=0.17$; group $\times$ time interaction, $\left.F_{(5,140)}=0.31, p=0.90\right)$. Global brain glucose utilization.

\section{Global brain glucose utilization}

After the placebo infusion, CMRglc measured for the entire brain did not differ significantly between the alcoholics and healthy volunteers. Global CMRglc for the healthy volunteers after the placebo infusion was $7.69 \pm 2.98 \mathrm{mg} / \mathrm{min}$ per $100 \mathrm{gm}$ of tissue (all values reported as mean $\pm \mathrm{SD}$ ); for the alcoholic subjects it was $7.00 \pm 0.69 \mathrm{mg} / \mathrm{min}$ per $100 \mathrm{gm}$ of tissue. The CMRglc of the entire brain increased in both healthy volunteers and alcoholics after mCPP infusion. The increase in CMRglc after mCPP was $0.74 \pm 1.00 \mathrm{mg} / \mathrm{min}$ per $100 \mathrm{gm}$ of tissue for the healthy volunteers and $0.35 \pm 0.21 \mathrm{mg} / \mathrm{min}$ per $100 \mathrm{gm}$ of tissue for the alcoholic subjects. Both of these increases were significant when tested against the null hypothesis of no increase in global CMRglc $\left(t_{(7)}=2.36, p<0.05\right.$ for healthy volunteers and $t_{(10)}=3.24, p<$ 0.05 for alcoholics). However, the size of the increase in wholebrain CMRglc did not differ significantly between the alcoholics and healthy volunteers ( $t$ test for independent groups with unequal variance; $t_{(14)}=1.26$, n.s.).

\section{Differences in regional brain glucose utilization after placebo: observed (absolute) and relative values}

After placebo administration Gaussian random field analysis of the observed glucose utilization values detected no regions of significantly different CMRglc between healthy volunteers and alcoholics. Similarly, there were no significant differences between alcoholics and healthy volunteers in the Gaussian random field analysis of relative glucose utilization.

\section{Change in regional brain glucose utilization after mCPP: observed (absolute) values}

Gaussian random field analysis of regional CMRglc after mCPP infusion revealed that pixels in the PET images of both alcoholics and healthy volunteers showed significant increases in observed regional CMRglc. Neither group demonstrated significant decreases anywhere in the brain after $\mathrm{mCPP}$ infusion. Although both alcoholics and healthy volunteers increased regional CMRglc after $\mathrm{mCPP}$, the pattern of increase was quite different between the two groups.

Among healthy volunteers mCPP administration led to significant increases in brain glucose metabolism in the following brain regions: the right medial and posterior orbital gyrus, the cerebellar hemispheres bilaterally, the left nucleus accumbens, the head of the caudate nucleus bilaterally, the anterior and medial-dorsal nuclei of the thalamus bilaterally, the middle frontal gyrus (left greater than right), the left insular cortex, the left middle temporal gyrus, and the posterior cingulate gyrus.

Among alcoholic subjects mCPP administration led to significant increases in brain glucose metabolism in larger areas of the cerebellum and posterior cingulate than it did in healthy volunteers, but, compared with the healthy volunteers, alcoholics showed a smaller area of significant mCPP-induced activation in the thalamus, almost no activation in the orbital cortices, and no activation at all in the head of the caudate nucleus. Furthermore, unlike healthy volunteer subjects, alcoholic subjects failed to show any significant increases in CMRglc in the middle frontal gyrus, although they did show small areas of activation in the insular cortex and inferior frontal gyrus on the right.

A detailed picture of the effects of $\mathrm{mCPP}$ can be seen in Figures $3-8$, which contrast mCPP-induced changes in CMRglc in healthy volunteer and alcoholic subjects.

mCPP-induced changes in CMRglc were examined separately for type I and type II alcoholics. The patterns observed in the two subgroups were very similar to each other and to the entire group of alcoholics. Both showed little, if any, activation in the orbital or prefrontal cortices and much less activation in basal ganglia and thalamus than was seen among healthy volunteers.

\section{Regional brain glucose utilization change after mCPP: relative values}

The anatomical distribution of significant increases in relative CMRglc after mCPP infusion among healthy volunteers was very 

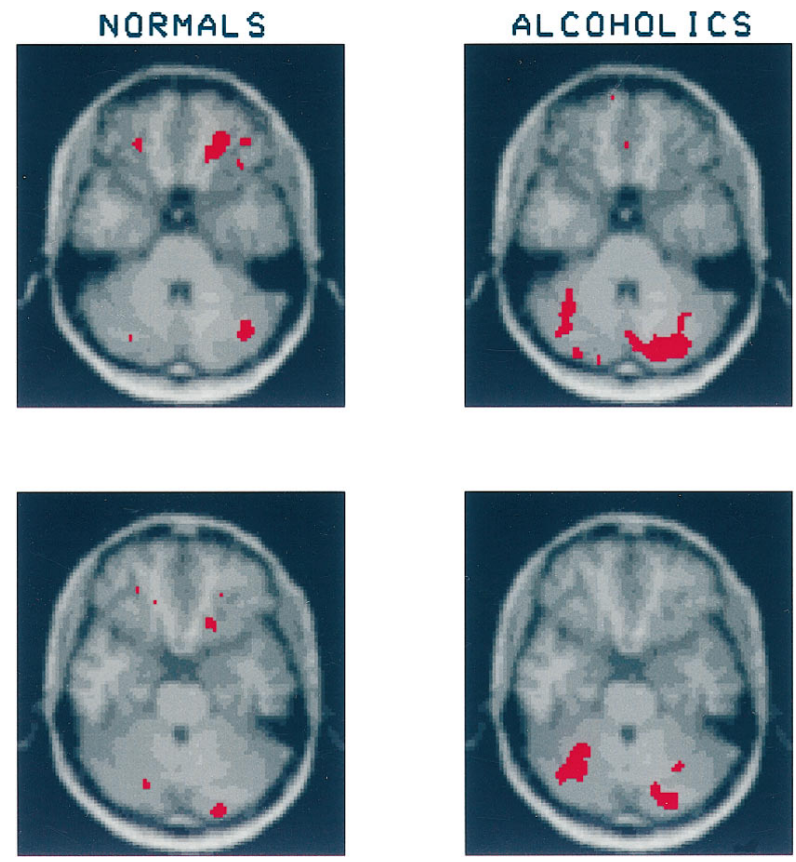

Figure 3. Each of the Figures 3-8 displays two pairs of contiguous axial slices from an MRI image of the brain of the healthy subject, which was used as a template onto which each subject's PET data were transformed. These slices correspond to the original PET slices collected parallel to the cantho-meatal lines and separated by $3.6 \mathrm{~mm}$. Superimposed in red on these MRI images are the regions that showed a significant increase in CMRglc after mCPP administration. The brain response of healthy volunteers is shown on the left and that of alcoholics on the right. To compare the magnitude of the regional $\mathrm{mCPP}$ response between alcoholics and healthy volunteers, we summed regions of significantly activated contiguous pixels (both within a slice and across adjacent slices) and calculated the mean CMRglc before and after mCPP. From these values we determined a percentage increase in glucose utilization after $\mathrm{mCPP}$. The volume of significant increase was determined by using the subject group (alcoholics or healthy volunteers) that showed the largest volume of significant activation for each brain region examined. In most brain regions the healthy volunteers had larger volumes of significant increase than the alcoholics, exceptions being the right and left cerebellum and the left posterior cingulate. No statistical comparison is made using these values because they are derived from a post hoc analysis of data already examined for statistical significance by the Gaussian random field method.

Figure 3 shows two contiguous slices through the orbital cortex. Among the healthy volunteers an area of significantly increased glucose utilization after mCPP can be seen in the right orbital cortex of both slices. The mean increase in CMRglc in significantly activated right orbital cortex was $27.6 \pm 20.1 \%$ (mean $\pm \mathrm{SD}$ ). Among alcoholics this same region showed a mean increase of $7.5 \pm 11.7 \%$. A different pattern occurs in the cerebellum, where alcoholics show a larger extent of significantly increased CMRglc. In the right cerebellum alcoholics increased glucose utilization by $16.3 \pm 9.9 \%$, whereas healthy volunteers increased by $15.8 \pm$ $17.2 \%$. In the left cerebellum alcoholics increased by $16.7 \pm 11.1 \%$, and healthy volunteers increased by $13.1 \pm 17.9 \%$.

similar to that seen with the use of observed CMRglc values; however, the total number of significant pixels was reduced by $\sim 50 \%$. Despite the overall reduction, three brain regions of the healthy volunteers showed nearly as many significantly activated relative CMRglc pixels as were present when change in absolute CMRglc was examined. These regions were the right medial orbital gyrus, the left nucleus accumbens, and the medial-dorsal nuclei of the thalamus bilaterally. Significant increases in relative CMRglc also were observed in a small area of the right cerebellar hemisphere, the left middle frontal gyrus, the right head of the
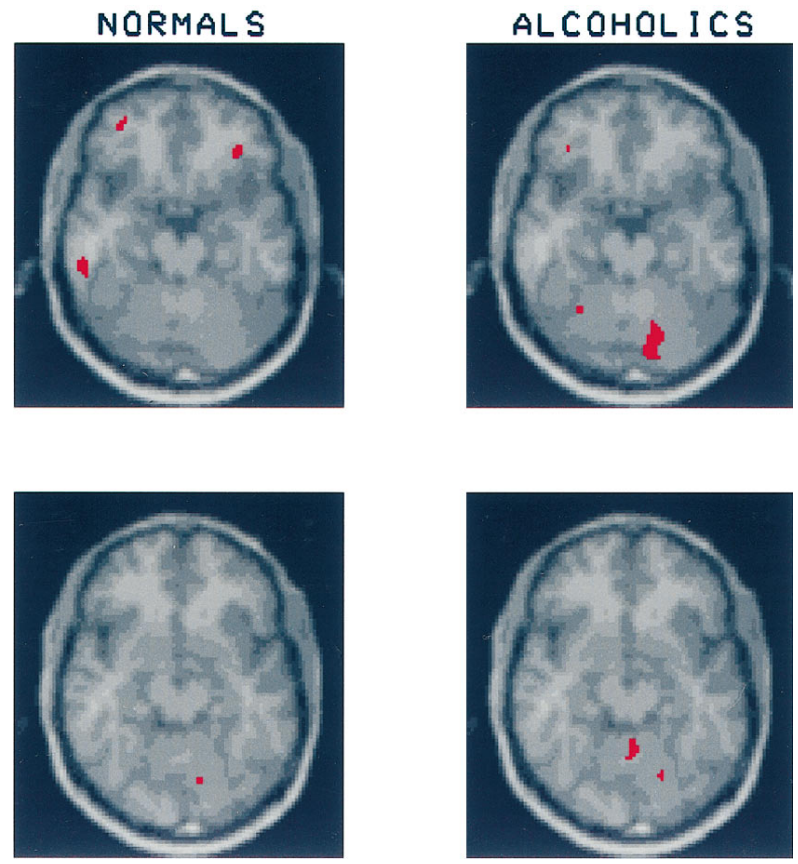

Figure 4. These slices through the superior aspects of the orbital cortex and cerebellum show three regions of significant activation in the healthy volunteers: one in the inferior temporal lobe on the left and bilateral regions in lateral orbital gyrus. Because these regions were relatively small and did not appear on contiguous slices, their mean CMRglc was not calculated. The area of significant activation seen in the right cerebellar hemisphere of the alcoholics was included in the calculation of mean CMRglc for the right cerebellar region described in Figure 3.

caudate nucleus, and the posterior cingulate. However, there were many fewer significantly activated pixels in these regions than when the effect of mCPP on absolute CMRglc was examined.

Among alcoholic subjects even fewer relative CMRglc pixels showed a significant increase after mCPP infusion than among the healthy volunteers. The largest area of increase in relative CMRglc among the alcoholic subjects occurred in the right cerebellar hemisphere. Small regions of significantly increased relative CMRglc were also present in the medial-dorsal nuclei of the thalamus bilaterally and the right inferior frontal gyrus. Only one pixel was increased significantly in the left nucleus accumbens.

\section{Differences between alcoholic and healthy volunteers and between type I and type II alcoholics}

After mCPP infusion Gaussian random field analysis comparing the change in observed CMRglc between alcoholic and healthy volunteers demonstrated an area of significantly greater increase in brain glucose utilization among the healthy volunteers. This region of difference was restricted to the anterior thalamus, right greater than left. An identical analysis performed by using relative CMRglc showed that healthy volunteers had significantly greater increase in glucose utilization after $\mathrm{mCPP}$ infusion restricted to a small area of the left nucleus accumbens.

After placebo infusion Gaussian random field analysis of regional CMRglc showed no significant differences between type I and type II alcoholics in either absolute or relative glucose utilization. Similarly, after mCPP infusion there were no significant differences in the mCPP-induced change in CMRglc detected between the subtypes of alcoholics. However, there were several circumscribed areas in the superior prefrontal cortex of type II alcoholics that had considerably (but not significantly) lower 

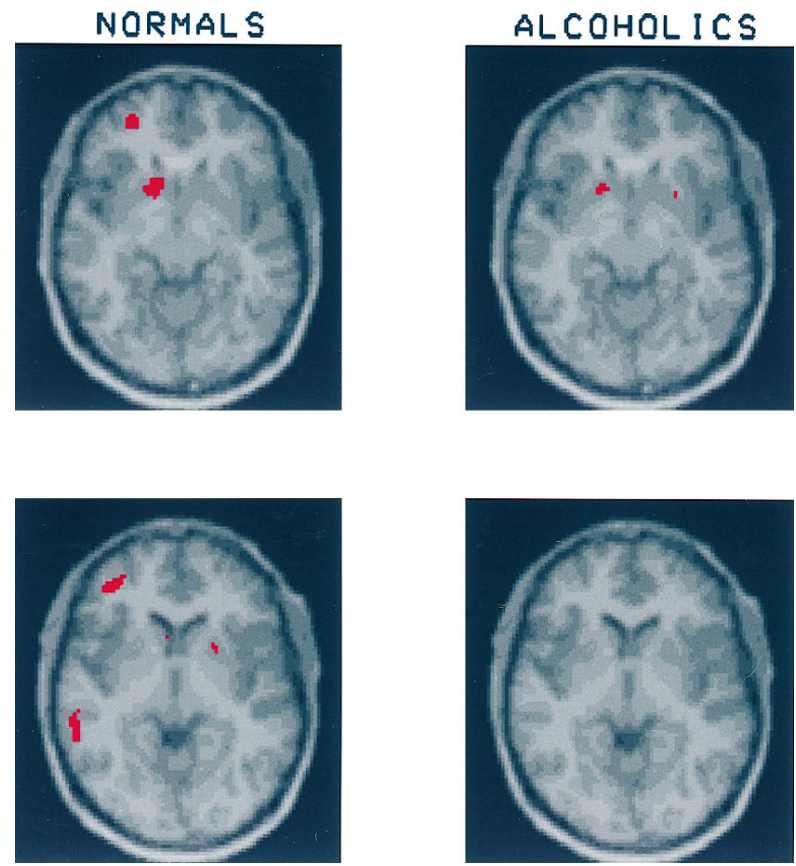

Figure 5. These slices through the ventral striatum show a region of significant increase in CMRglc in the left nucleus accumbens of both the healthy volunteers and the alcoholics. Among the healthy volunteers glucose uptake in this region increased by $31.2 \pm 23.8 \%$; among the alcoholics the increase was $13.7 \pm 19.3 \%$. Also visible on these slices is a region of significant activation in the left middle frontal gyrus of the healthy volunteers (increase in CMRglc $=25.6 \pm 19.2 \%$ ). [No corresponding region of activation is detectable in the alcoholics (increase in CMRglc $=4.4 \pm 8.9 \%)$.]

change in CMRglc than observed in type I alcoholics. A power analysis of these data indicates that our sample size is too small to be able to detect confidently any significant CMRglc differences between type I and type II alcoholics in superior prefrontal cortex. A sample approximately twice as large as the current one would be required to obtain a power of 0.80 for detecting a difference of $1 \mathrm{SD}$.

\section{Correlations between changes in glucose utilization, mood, prolactin, and ACTH after mCPP}

The mean change in CMRglc was determined for the contiguous, significantly activated pixels in 14 brain regions as described and illustrated in Figures 3-8. The brain regions used were right orbital cortex, right and left cerebellar hemispheres, left nucleus accumbens, left middle frontal gyrus (inferior portion), left and right head of the caudate nucleus, left and right ventral thalamus, left and right dorsal thalamus, left and right middle frontal gyrus (superior portion), and left posterior cingulate. Pearson correlations were computed to examine the relationships between the change in CMRglc in each of these brain regions induced by mCPP and the change in self-rated feelings of panic, as well as the maximum change in prolactin and $\mathrm{ACTH}$ after $\mathrm{mCPP}$.

The most consistently high correlations between mCPPinduced change in regional CMRglc and neuroendocrine or emotional effects of mCPP occurred in the right orbital cortex (Fig. 9), where the correlations with change in CMRglc were as follows: ACTH, $r=0.46, p<0.02$; prolactin, $r=0.56, p<0.001$; feelings of panic, $r=0.47, p<0.02$. When adjusted for multiple comparisons, only the correlation between change in glucose utilization and prolactin was significant. Significant correlations between
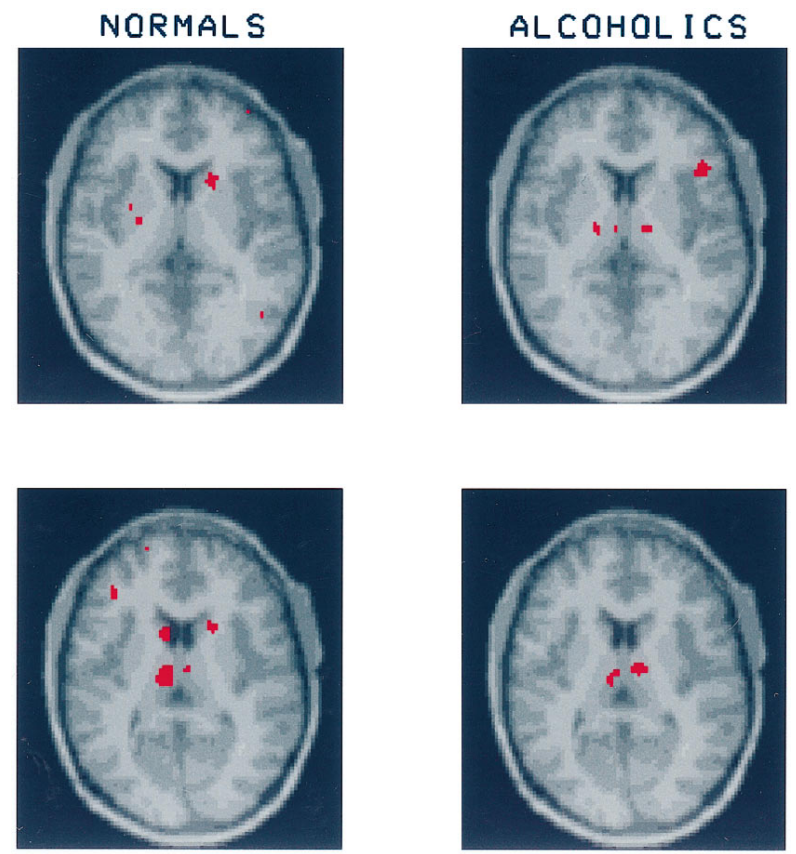

Figure 6. Slices at the level of the ventral thalamus show that in response to $\mathrm{mCPP}$ healthy volunteers significantly activate in the head of the caudate nucleus bilaterally (increase in CMRglc: right caudate, $28.3 \pm$ $21.9 \%$; left caudate, $35.1 \pm 31.2 \%$ ). In the corresponding regions of the striatum the alcoholics show no significant increase in glucose uptake (increase in CMRglc: right caudate, $8.2 \pm 18.5 \%$; left caudate, $9.3 \pm$ $23.8 \%$ ). Both healthy volunteers and alcoholics have regions of significant increase in the ventral thalamus (for healthy volunteers the increase in CMRglc of the right ventral thalamus was $10.5 \pm 32.5 \%$ and in the left ventral thalamus, $15.6 \pm 22.8 \%$; for alcoholics the increase in CMRglc of right ventral thalamus was $52.6 \pm 47.7 \%$ and in the left ventral thalamus, $22.1 \pm 15.6 \%$ ). There is also an area of significantly increased glucose utilization in the right opercular cortex of the alcoholics, which is not present among the healthy volunteers.

prolactin and change in CMRglc also were present in three additional brain regions: the left inferior middle frontal gyrus, $r=$ $0.55, p<0.002$; the right head of the caudate nucleus, $r=0.57$, $p<0.001$; and the left dorsal thalamus, $r=0.55, p<0.002$. High (but not significant correlations when adjusted for multiple testing) also were present between feelings of panic and change in glucose utilization after $\mathrm{mCPP}$ in the left inferior middle frontal gyrus, $r=0.45, p<0.03$ and the right dorsal thalamus, $r=0.41$, $p<0.04$. Other than the right orbital cortex, only one other brain region showed a high (but not significant) correlation with ACTH. The change in CMRglc in the left dorsal thalamus correlated with the ACTH response, $r=0.36, p<0.05$. No other correlations achieved the level of an uncorrected $p<0.05$.

\section{DISCUSSION}

mCPP failed to induce "craving" for alcohol or any of the subjective experiences associated with alcohol use. Because both we and others have observed mCPP-induced alcohol-related subjective effects in other settings, their absence in this study likely is attributable to the influence of the PET environment. Lying inside a large complex machine with one's head restrained by a thermoplastic mask, cannulas in an artery of one arm and a vein of the other while physicians inject two experimental drugs, one of which is radioactive, is probably even less conducive to experiencing subjective alcohol-like effects than the usual clinical research setting. 

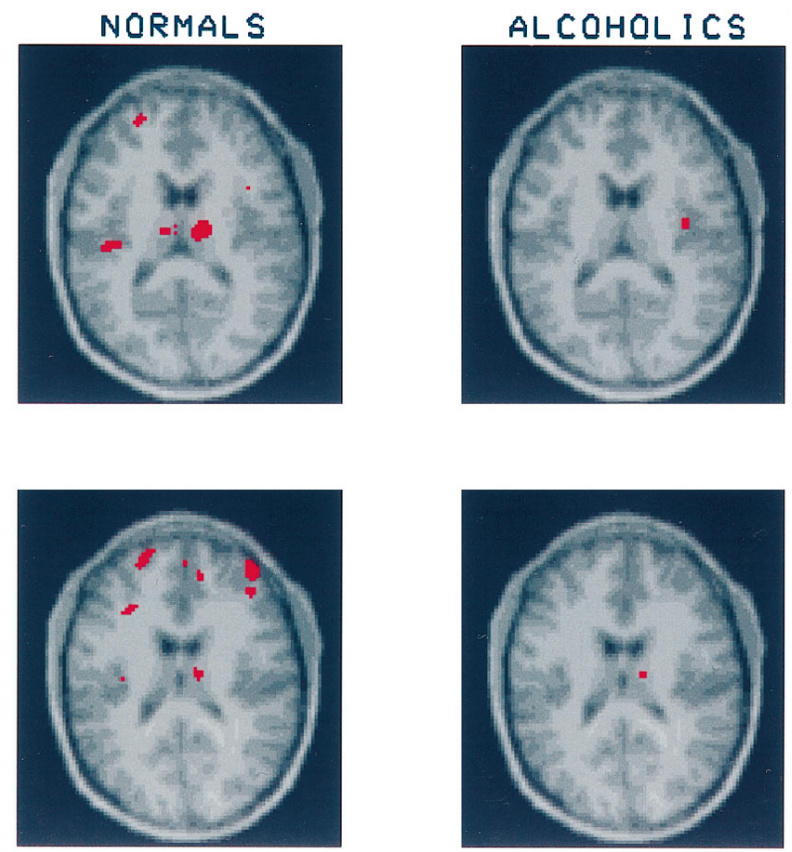

Figure 7. On these slices through the dorsal thalamus healthy volunteers show significant increases in glucose uptake in several regions, including middle frontal gyrus bilaterally, dorsal thalamus bilaterally, and left insular cortex. In contrast, the alcoholics show only small regions of significant activation in right dorsal thalamus and right insula. The percentages of increase in CMRglc after mCPP are as follows: for healthy volunteers, right middle frontal gyrus $=19.4 \pm 17.3 \%$, left middle frontal gyrus $=$ $21.4 \pm 16.1 \%$, right dorsal thalamus $=30.8 \pm 30.3 \%$, left dorsal thalamus $=32.4 \pm 26.5 \%$; for the alcoholics, right middle frontal gyrus $=6.0 \pm$ $9.9 \%$, left middle frontal gyrus $=3.9 \pm 7.8 \%$, right dorsal thalamus $=$ $13.3 \pm 12.0 \%$, left dorsal thalamus $=9.5 \pm 12.4 \%$.

Although mCPP did not induce different subjective effects in alcoholics as compared with controls, it did induce different patterns of brain glucose utilization, and consistent with previous studies, the ACTH response to $\mathrm{mCPP}$ was blunted among alcoholics (Krystal et al., 1994; George et al., 1997). Both healthy volunteers and alcoholics showed significant increases in absolute CMRglc after mCPP infusion; however, alcoholics showed less regional activation, particularly in the frontal lobes. There has been only one study of the effects of mCPP on brain glucose uptake in rodents (Freo et al., 1990), and this study found a reduction of CMRglc. However, these results should not be compared directly with our findings, because the dose of mCPP used in the rodent study was $>30$ times greater than the dose we used, and it resulted in clear behavioral impairment.

In our study glucose utilization among healthy volunteers increased primarily in the orbital cortex, prefrontal cortex, and subcortical components of the basal ganglia-thalamocortical circuit associated with these cortical regions: namely, the nucleus accumbens, the head of the caudate nucleus, and the anterior and medial-dorsal thalamus. In contrast, alcoholics showed virtually no increase in orbital and prefrontal cortices, and they failed to increase CMRglc as much as controls did in the nucleus accumbens, the head of the caudate nucleus, and the anterior and medial-dorsal thalamus. There were two brain regions in which the alcoholics showed greater increase in glucose utilization than healthy volunteers: the cerebellar hemispheres and the posterior cingulate cortex.

In healthy volunteers mCPP appears to increase significantly
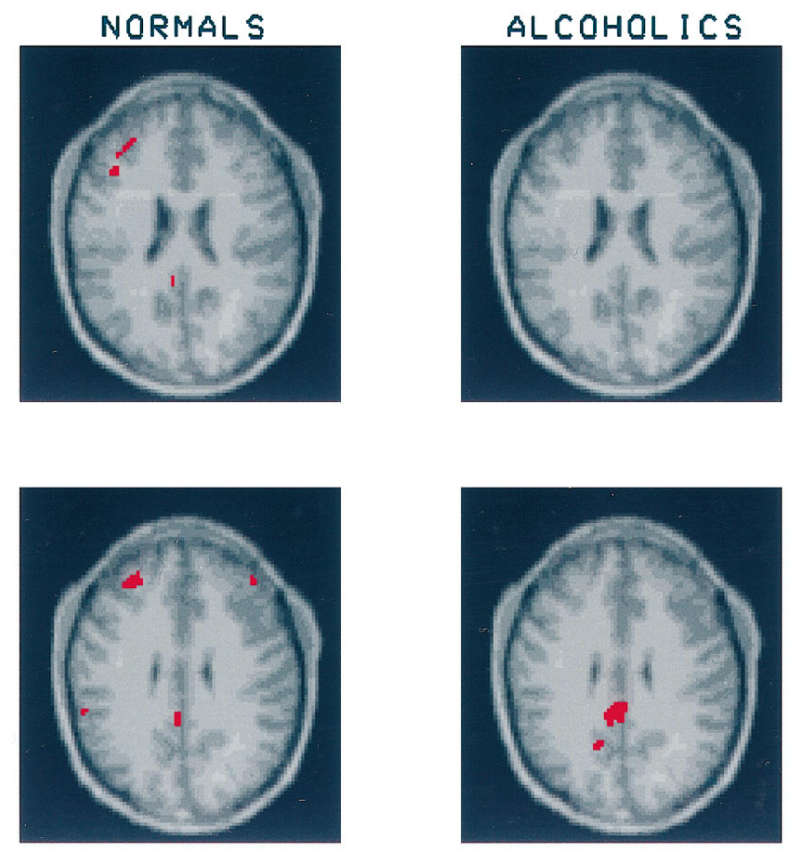

Figure 8. These slices begin at the top edge of the corpus callosum and demonstrate significant increases in CMRglc in the posterior cingulate of both the alcoholics $(10.8 \pm 13.5 \%)$ and healthy volunteers $(21.7 \pm 28.7 \%)$. Continuation of a region of activation in the left middle frontal gyrus of the healthy volunteers also can be seen.

the CMRglc in brain regions that are almost exclusively part of basal ganglia-thalamocortical circuits. On the basis of known functional neuroanatomy (Alexander et al., 1986), there seem to be two distinct basal ganglia-thalamocortical circuits activated by $\mathrm{mCPP}$. One is a circuit involving orbital cortex, anterior and medial-dorsal thalamus, and ventral striatum, including the nucleus accumbens. The other circuit connects prefrontal cortex, medial-dorsal thalamus, and dorsal striatum.

Five basal ganglia-thalamocortical circuits have been described in the brains of nonhuman primates (including the two mentioned above), and it is likely that more are present in the human brain (Alexander et al., 1986). In general, these circuits connect several functionally related areas of cortex with the striatum, which processes cortical information, sends it on to the globus pallidus/ substantia nigra reticulata, which in turn projects to the thalamus where the information is combined again with information from the related cortical areas, and finally is sent back to one of the cortical regions. The cortical region, which receives the output of the thalamus, is never a sensory region but always an area in the frontal lobes involved in motor, emotional, or cognitive behavior.

Given this anatomy, it is not surprising that several workers have suggested that these circuits are involved in the sequential selection of one output from among several competing potential responses (Barker, 1988; Kropotov et al., 1992; Houk and Wise, 1995) and that these circuits may be particularly important in the inhibition of common responses in contexts in which the usual response is not optimally adaptive (Henik et al., 1993; Marsden and Obeso, 1994). The specific function of each basal gangliathalamocortical circuit depends on the part of the frontal cortex it serves. Thus the circuit that includes the orbital cortex may regulate and monitor emotional and motivational states, whereas the circuit that includes the prefrontal cortex may regulate processes involving working memory. 

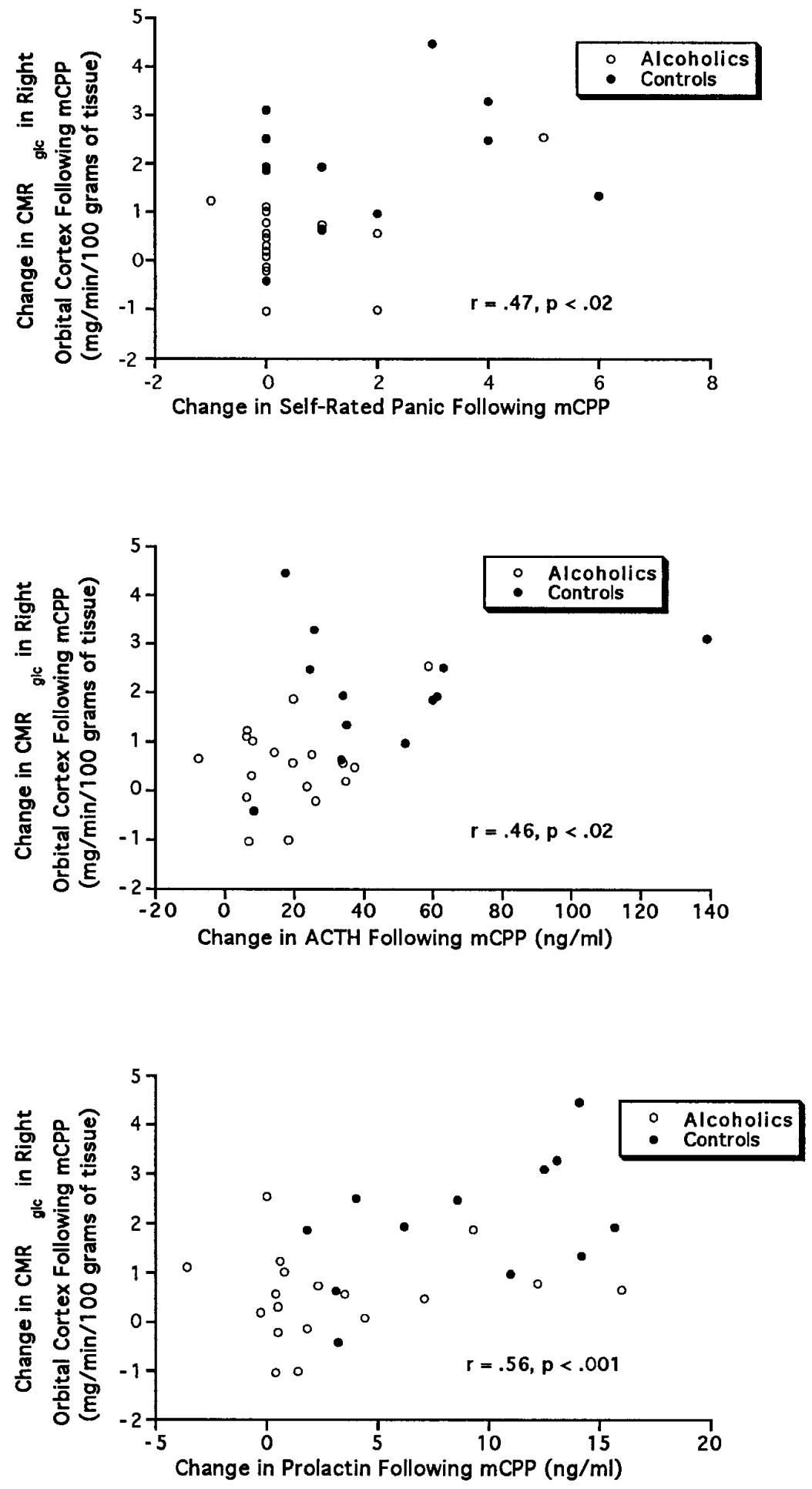

Figure 9. These three panels show the relationship between the change in CMRglc in the right orbital cortex induced by mCPP administration and (top to bottom) the change in self-rated feelings of panic, peak change in $\mathrm{ACTH}$, and peak change in prolactin.

How the failure of the alcoholics in our study to activate prefrontal and orbital basal ganglia-thalamocortical circuits in response to a serotonin agonist relates to the minimal cognitive dysfunction usually observed in relatively young alcoholics (Eckardt et al., 1995), such as those in this study, is uncertain. However, even young cognitively intact alcoholics do show an impaired ability to use language to describe emotions (Kauhanen et al., 1992; Ziolkowski et al., 1995). This deficit, known as alexithymia, reasonably could be considered as related to both left prefrontal and orbital frontal dysfunction. Does the hyporesponsivity in the prefrontal and orbital basal ganglia-thalamocortical circuits that we observed among alcoholics underlie alexithymia in alcoholism? Functional imaging studies specifically designed to investigate the relationship between language and emotion will be needed to answer this question.

The distribution of brain regions activated by mCPP in healthy volunteers is similar to the patterns of activation produced by anxiogenic behavioral challenge studies in subjects with obsessivecompulsive disorder (OCD; Rauch et al., 1994; Breiter et al., 1996; Cottraux et al., 1996). On the basis of a possible psycholog- 
ical similarity between craving for alcohol and the compulsion to perform ritualized behaviors among individuals with OCD, Modell et al. (1990) proposed that the orbital frontal basal gangliathalamocortical circuit mediates the alcohol craving and the loss of control that are characteristic of alcoholism. However, in contrast to our results, Modell et al. hypothesized that increased activity in the orbital frontal basal ganglia-thalamocortical circuit would be associated with alcoholic loss of control. Because during the scans mCPP did not elicit the subjective experience of craving or loss of control, our results do not disprove the hypothesis that alcoholic craving and loss of control are associated with hyperfunction of the orbital frontal basal ganglia-thalamocortical circuit. However, we believe that our results are more consistent with an alternative hypothesis, namely that, rather than being hyperactive, the orbital frontal basal ganglia-thalamocortical circuit and the prefrontal basal ganglia-thalamocortical circuit, as well, are hyporesponsive among alcoholics. That is, drugs or behaviors that would either increase or decrease activity in these circuits among healthy volunteers produce a smaller change in the activity of these circuits among alcoholics.

In a recent PET study Volkow et al. (1993) reported decreased response to the CMRglc-lowering effect of lorazepam (a benzodiazepine functional $\mathrm{GABA}_{\mathrm{A}}$ receptor agonist) among early onset alcoholics, a population suggested to be characterized by low CSF 5-HIAA concentrations (Virkkunen and Linnoila, 1993). Compared with control subjects, early onset alcoholics had significant attenuations of the benzodiazepine-induced reduction in CMRglc in three brain regions: the orbital frontal cortex, the basal ganglia, and the thalamus. Similarly, in a study of nonhuman primates we found that the animals with the lowest CSF 5-HIAA had the highest CMRglc in the same three brain regions, the orbital frontal cortex, the basal ganglia, and the thalamus (Doudet et al., 1995). Because the animals in this study were anesthetized, we interpreted the negative correlation between CSF 5-HIAA and CMRglc in the orbital frontal basal ganglia-thalamocortical circuit as indicative of hyporesponsivity of this circuit among low CSF 5-HIAA monkeys.

If alcoholics have hyporesponsive orbital and prefrontal basal ganglia-thalamocortical circuits, what role does serotonin play in this hyporesponsivity? It is clear that the reduced response among alcoholics is not restricted exclusively to pharmacological interventions affecting serotonin receptors, because hyporesponsivity has been observed after GABA $_{\mathrm{A}}$ agonists (Volkow et al., 1993; Doudet et al., 1995). Although these results are incompatible with exclusive serotoninergic modulation of the responsivity of basal ganglia-thalamocortical circuits, the correlation between CSF 5-HIAA and CMRglc we found in monkeys suggests that reduced serotoninergic activity may be associated with this hyporesponsivity. Unfortunately, CSF was not available from the subjects in the current study, so we could not examine directly the relationship between CSF 5-HIAA and CMRglc among our subjects.

The most important limitation of this study is the failure of mCPP, when given to subjects in the PET scanner, to induce any of the subjective experiences associated with alcohol craving or use. The absence of induction of craving makes it impossible to say for certain how the metabolic changes induced by $\mathrm{mCPP}$ relate to alcohol craving. Another possible limitation of this study relates to the fact that each individual's PET data were transformed to fit a standard brain. Although this is the most commonly used technique for the analysis of PET data, it is possible that anatomical differences between healthy volunteers and alcoholics could have introduced artifactual differences. However, we believe that this is unlikely, because anatomical differences would affect both pre- and post-mCPP scans, and there were no differences between the groups when the pre-mCPP scans were compared. Nonetheless, future studies would benefit from having full volumetric MRI scan available from all subjects so that intrasubject registration of PET with MRI could allow unequivocal identification of specific brain regions to be compared across groups.

Despite these limitations our results demonstrate that, among healthy volunteers, mCPP activates orbital and prefrontal cortices, along with associated striatal and thalamic regions. These areas are much less activated by mCPP among alcoholics. Which receptors $\mathrm{mCPP}$ acts on to produce these activations is not known. However, mCPP possesses high affinity for the $5 \mathrm{HT}_{2 \mathrm{C}}$ receptors, and this receptor subtype is the most common serotonin receptor in the brain (Pompeiano et al., 1994; Wright et al., 1995). It is found primarily in cortical and subcortical structures of the limbic system, although other receptor subtypes, most notably $5 \mathrm{HT}_{2 \mathrm{~A}}$, are also present in these regions. Of course in this study, as in any functional imaging study of drug response, it is impossible to say whether the activations observed result from drug effects directly on the structure activated or represent indirect effects from some other brain region.

\section{REFERENCES}

Adler RJ (1981) The geometry of random fields. New York: Wiley.

Alexander G, DeLong M, Strick P (1986) Parallel organization of functionally segregated circuits linking basal ganglia and cortex. Annu Rev Neurosci 9:357-381.

American Psychological Association (1990) Structured clinical interview for Diagnostic and Statistical Manual III-R, patient, non-patient editions. Washington, DC: American Psychiatric.

Barker R (1988) How does the brain control its own activity? A new function for the basal ganglia. J Theor Biol 131:497-507.

Benkelfat C, Murphy DL, Hill JL, George DT, Nutt D, Linnoila M (1991) Ethanol-like properties of the serotonergic partial agonist $m$-chlorophenylpiperazine in chronic alcoholic patients [letter]. Arch Gen Psychiatry 48:383.

Besel P, McKay N (1992) A method for registration of 3-D shapes. IEEE Trans Patt Anal Machine Intell 14:239-256.

Breiter HC, Rauch SL, Kwong KK, Baker JR, Weisskoff RM, Kennedy DN, Kendrick AD, Davis TL, Jiang A, Cohen MS, Stern CE, Belliveau JW, Baer L, O'Sullivan RL, Savage CR, Jenike MA, Rosen BR (1996) Functional magnetic resonance imaging of symptom provocation in obsessive-compulsive disorder. Arch Gen Psychiatry 53:595-606.

Brooks RA, DiChiro G, Zukerberg BW, Bairamian D, Larson SM (1985) Test-retest studies of cerebral glucose metabolism with F-18deoxyglucose. J Nucl Med 26:68.

Brooks RA, DiChiro G, Zukerberg BW, Bairamian D, Larson SM (1987) Test-retest studies of cerebral glucose metabolism using fluorine-18 deoxyglucose: validation of method. J Nucl Med 28:53-59.

Chang JY, Duara R, Barker W, Apicella A, Finn R (1987) Two behavioral states studied in a single PET/FDG procedure: theory, method, and preliminary results. J Nucl Med 28:852-860.

Chang JY, Duara R, Barker W, Apicella A, Yoshii F, Kelley RE, Ginsberg MD, Boothe TE (1989) Two behavioral states studied in a single PET/FDG procedure: error analysis. J Nucl Med 30:93-105.

Cottraux J, Gerard D, Cinotti L, Froment JC, Deiber MP, Le Bars D, Galy G, Millet P, Labbe C, Lavenne F, Bouvard M, Mauguiere F (1996) A controlled positron emission tomography study of obsessive and neutral auditory stimulation in obsessive-compulsive disorder with checking rituals. Psychiatry Res 60:101-112.

Doudet D, Hommer D, Higley D, Andreasen P, Momenan R, Suomi S, Linnoila M (1995) Cerebral glucose metabolism, CSF 5-HIAA, and aggressive behavior in rhesus monkeys. Am J Psychiatry 152:1782-1787.

Duara R, Barker WW, Chang J, Yoshii F, Lowenstein DA, Pascal S (1992) Viability of neocortical function shown in behavioral activation state PET studies in Alzheimer disease. J Cereb Blood Flow Metab 12:927-934.

Eckardt MJ, Parker ES, Noble EP, Feldman DJ, Gottschalk LA (1978) 
Relationship between neuropsychological performance and alcohol consumption in alcoholics. Biol Psychiatry 13:551-565.

Eckardt MJ, Stapleton JM, Rawlings RR, Davis EZ, Grodin DM (1995) Neuropsychological functioning in detoxified alcoholics between 18 and 35 years of age. Am J Psychiatry 152:53-59.

Freo U, Soncrant TT, Ricchieri GL, Wozniak KM, Larson DM, Rapoport SI (1990) Time courses of behavioral and regional cerebral metabolic responses to different doses of meta-chlorophenylpiperazine in awake rats. Brain Res 511:209-216.

George DT, Benkelfat C, Nutt DJ, Hill JL, Phillips MJ, Wynne D, Schmitz J, Murphy DL, Linnoila M (1997) A comparison of behavioral and biochemical responses to meta-chlorophenylpiperazine in subtypes of alcoholics. Am J Psychiatry 154:81-87.

Hamik A, Peroutka SJ (1989) 1-(m-Chlorophenyl)piperazine (mCPP) interactions with neurotransmitter receptors in the human brain. Biol Psychiatry 25:569-575.

Henik A, Singh J, Beckley DJ, Rafal RD (1993) Disinhibition of automatic word reading in Parkinson's disease. Cortex 29:589-599.

Houk JC, Wise SP (1995) Distributed modular architectures linking basal ganglia, cerebellum, and cerebral cortex: their role in planning and controlling action. Cereb Cortex 5:95-110.

Hoyer D (1988) Functional correlates of serotonin 5-HT1 recognition sites. J Recept Res 8:59-81.

Kahn RS, Wetzler S (1991) $m$-Chlorophenylpiperazine as a probe of serotonin function. Biol Psychiatry 30:1139-1166.

Kauhanen J, Julkunen J, Salonen JT (1992) Coping with inner feelings and stress: heavy alcohol use in the context of alexithymia. Behav Med 18:121-126.

Kropotov JD, Etlinger SC, Ponomarev VA, Kuznetzov MA, Trofimova LG (1992) Event-related neuronal responses in the human striopallido-thalamic system. II. Cognitive functions. Electroencephalogr Clin Neurophysiol 84:386-393.

Krystal JH, Webb E, Cooney N, Kranzler HR, Charney DS (1994) Specificity of ethanol-like effects elicited by serotonergic and noradrenergic mechanisms. Arch Gen Psychiatry 51:898-911.

Krystal JH, Webb E, Cooney NL, Kranzler HR, Southwick SW, Heninger GR, Charney DS (1996) Serotonergic and noradrenergic dysregulation in alcoholism: $m$-chlorophenylpiperazine and yohimbine effects in recently detoxified alcoholics and healthy comparison subjects. Am J Psychiatry 153:83-92.

Marquardt D (1963) An algorithm for least-squares estimation of nonlinear parameters. J Soc Ind Appl Math 12:431-441.

Marsden CD, Obeso JA (1994) The functions of the basal ganglia and the paradox of stereotaxic surgery in Parkinson's disease [comments]. Brain 117:877-897.
Modell JG, Mountz JM, Beresford TP (1990) Basal ganglia/limbic striatal and thalamocortical involvement in craving and loss of control in alcoholism. J Neuropsychiatry Clin Neurosci 2:123-144.

Pompeiano M, Palacios JM, Mengod G (1994) Distribution of the serotonin 5-HT2 receptor family mRNAs: comparison between 5-HT2A and 5-HT2C receptors. Brain Res Mol Brain Res 23:163-178.

Rauch SL, Jenike MA, Alpert NM, Baer L, Breiter HC, Savage CR, Fischman AJ (1994) Regional cerebral blood flow measured during symptom provocation in obsessive-compulsive disorder using ${ }^{15} \mathrm{O}$ labeled carbon dioxide and positron emission tomography. Arch Gen Psychiatry 51:62-70.

Ruttimann UE, Andreasen PJ, Rio D (1995) Head motion during positron emission tomography: is it significant? Psychiatry Res 61:43-51.

Sanders-Bush E, Breeding M (1990) Serotonin 1C receptor reserve in choroid plexus masks receptor supersensitivity. J Pharmacol Exp Ther 252:984-988.

Schoeffter P, Hoyer D (1989) Interaction of arylpiperazines with 5-HT1A, 5-HT1B, 5-HT1C, and 5-HT1D receptors: do discriminatory 5-HT1B receptor ligands exist? Naunyn Schmiedebergs Arch Pharmacol 339:675-683.

Selzer ML (1971) The Michigan alcoholism screening test: the quest for a new diagnostic instrument. Am J Psychiatry 127:1653-1658.

Thevenaz P, Ruttimann UE, Unser M (1995) Interactive multi-scale registration without landmarks. Proc IEEE 3:228-231.

Unser M, Thevenaz P, Lee C, Ruttimann UE (1995) Registration and statistical analysis of PET images using wavelet transform. IEEE Eng Med Biol Sept/Oct:603-611.

Virkkunen M, Linnoila M (1993) Brain serotonin, type II alcoholism, and impulsive violence. J Stud Alcohol [Suppl] 11:163-169.

Volkow ND, Wang G-K, Hitzemann R, Fowler JS, Wolf AP, Pappas N, Biegon A, Dewey SL (1993) Decreased cerebral response to inhibitory neurotransmission in alcoholics. Am J Psychiatry 150:417-422.

von Knorring A-L, Bohman M, von Knorring L, Oreland L (1985) Platelet MAO activity as a biological marker in subgroups of alcoholism. Acta Psychiatr Scand 72:51-58.

Worsley KJ, Evans AC, Marrett S, Neelin P (1992) A three-dimensional statistical analysis for CBF activation studies in human brain. J Cereb Blood Flow Metab 12:900-918.

Wright DE, Seroogy KB, Lundgren KH, Davis BM, Jennes L (1995) Comparative localization of serotonin $1 \mathrm{~A}, 1 \mathrm{C}$, and 2 receptor subtype mRNAs in rat brain. J Comp Neurol 351:357-373.

Ziolkowski M, Gruss T, Rybakowski JK (1995) Does alexithymia in male alcoholics constitute a negative factor for maintaining abstinence? Psychother Psychosom 63:169-173. 